\title{
Inhaltsverzeichnis
}

Verzeichnis der Bearbeiter der 13. Auflage $-\mathrm{V}$

Vorwort — VII

Abkürzungsverzeichnis - $\mathrm{XI}$

Schrifttum und abgekürzt zitierte Literatur —XXXIII

Strafgesetzbuch -1

BESONDERER TEIL -1

\section{SIEBENTER ABSCHNITT}

Straftaten gegen die öffentliche Ordnung - 1

$\S 123$ Hausfriedensbruch - 1

$\S 124$ Schwerer Hausfriedensbruch - 37

$\S 125$ Landfriedensbruch - 44

$\S 125$ a Besonders schwerer Fall des Landfriedensbruchs - 103

$\S 126$ Störung des öffentlichen Friedens durch Androhung von Straftaten -124

$\S 127$ Bildung bewaffneter Gruppen — 146

$\S 128$ weggefallen — 162

$\S 129$ Bildung krimineller Vereinigungen - 163

$\S 129$ a Bildung terroristischer Vereinigungen -271

$\S 129 \mathrm{~b}$ Kriminelle und terroristische Vereinigungen im Ausland Erweiterter Verfall und Einziehung - 360

$\S 130$ Volksverhetzung - 395

$\S 130$ a Anleitung zu Straftaten -511

$\S 131$ Gewaltdarstellung - 534

$\S 132$ Amtsanmaßung - 565

$\S 132 \mathrm{a}$ Mißbrauch von Titeln, Berufsbezeichnungen und Abzeichen - 585

$\S 133$ Verwahrungsbruch -616

$\S 134$ Verletzung amtlicher Bekanntmachungen - 636

$\S 135$ weggefallen - 641

$\S 136$ Verstrickungsbruch; Siegelbruch -642

$\S 137$ weggefallen - 663

$\S 138$ Nichtanzeige geplanter Straftaten - 664

$\S 139$ Straflosigkeit der Nichtanzeige geplanter Straftaten -690

$\S 140$ Belohnung und Billigung von Straftaten — 705

$\S 141$ weggefallen -723

§142 Unerlaubtes Entfernen vom Unfallort — 724

$\S 143$ weggefallen -875

$\S 144$ weggefallen - 876

$\S 145$ Missbrauch von Notrufen und Beeinträchtigung von Unfallverhütungs- und Nothilfemitteln -877

$\S 145 a$ Verstoß gegen Weisungen während der Führungsaufsicht — 899

$\S 145 \mathrm{~b}$ weggefallen — 924

$\S 145 \mathrm{c}$ Verstoß gegen das Berufsverbot - 925

$\S 145 d$ Vortäuschen einer Straftat — 941

Sachregister -959 
